\section{$\underset{\substack{\text { hommes } \\ \text { \& migrations }}}{ }$}

\section{Hommes \& migrations}

Revue française de référence sur les dynamiques

migratoires

$1315 \mid 2016$

Ondes de choc

\title{
Joseph Roth (traduit de l'allemand, préfacé et annoté par Alexis Tautou), Viens à Vienne je t'attends
}

Paris, L'Herne, 2015, 64 pages, 7,50€

\section{Mustapha Harzoune}

\section{(2) OpenEdition}

Journals

Édition électronique

URL : http://journals.openedition.org/hommesmigrations/3768

DOI : $10.4000 /$ hommesmigrations.3768

ISSN : 2262-3353

Éditeur

Musée national de l'histoire de l'immigration

Édition imprimée

Date de publication : 1 juillet 2016

Pagination : 154

ISBN : 978-2-919040-36-0

ISSN : 1142-852X

Référence électronique

Mustapha Harzoune, « Joseph Roth (traduit de l'allemand, préfacé et annoté par Alexis Tautou), Viens à Vienne je t'attends », Hommes \& migrations [En ligne], 1315 | 2016, mis en ligne le 01 juillet 2016, consulté le 24 septembre 2020. URL : http://journals.openedition.org/hommesmigrations/3768 ; DOI : https://doi.org/10.4000/hommesmigrations.3768 


\section{Joseph Roth}

(traduit de l'allemand, préfacé et annoté par Alexis Tautou)

Viens à Vienne

je t'attends

Paris, L'Herne, 2015, 64 pages, 7,50 €

L'ouvrage satisfera les familiers ou les curieux de l'écrivain autrichien, né en 1894 dans une famille juive de Galicie, témoin des dernières heures de l'Empire austro-hongrois, qui vécut exilé avant de se réfugier à Paris où il mourut en mai 1939. Les deux récits qui le composent - Mendel, le porteur d'eau et Au neuvième jour d'Av-constituent les prémices de romans à venir. On y retrouve les thèmes chers à Joseph Roth : le déracinement, la nostalgie d'un monde disparu, le shtetl et son condensé d'humanité, l'errance et l'exil politique.

Le lecteur, peu familier de l'auteur de La Marche de Radetzky, peu ou pas nostalgique d'un monde disparu, mais intéressé par la figure de l'exil, lira, lui, avec profit cette prose si proche des préoccupations modernes. II suivra la trajectoire du vieux Mendel, ce porteur d'eau juif qui n'a jamais quitté sa petite ville de Galicie mais dont les trois fils sont partis qui à Vienne, à Berlin ou en Amérique. Ici, il y a la guerre et un projet municipal d'installer des canalisations d'eau. " Il avait le choix de perdre son gagne-pain ou de partir rejoindre un de ses fils. "Dans la guerre entre Russes et Autrichiens, Mendel souhaite la victoire de ces derniers : "II n'y avait pas de pogroms en Allemagne. Alors que l'on tuait les Juifs en Russie. "Mendel doit partir. Il ira chez son fils Anselm, à Vienne, la grande ville, envahi par " une joie effrayante".

Court récit, mais d'une densité - et d'une sensibilité - aux résonances universelle et intemporelle. Tous les thèmes de l'exil y sont déclinés. Qu'il s'agisse des raisons du départ, de la vulnérabilité du voyageur, de l'arrivée à Vienne et des premières impressions, de l'épreuve de l'administration, des rapports avec la police... Du racisme. Ces réfugiés Naphtali, Korhus, ou Benjamin - sont devenus marchands par nécessité.. "C'était la guerre dans le monde, les gens mouraient à l'entour, et les vivants, eux, devaient bien vivre. »

Chez son fils, l'eau coule au robinet, Mendel entend le goutte-à-goutte. "Pour la première fois, il ressentit un début d'appartenance à l'eau, à cet élément qui l'avait fait vivre pendant plus de cinquante ans. " Comme l'eau, fluide, claire et disponible, il se montre curieux, ouvert à son nouvel environnement. Mendel " qui comptait soixante-deux printemps, avait l'impatience de la jeunesse". Dans les livres de la bibliothèque ou en discutant avec "le philosophe » Gabriel Tucher, Mendel se nourrit de connaissances nouvelles. "L'esprit ouvert ", il veut comprendre ce monde dans lequel il a été projeté. II en perd ses repères. Lui qui priait chaque jour " ne savait plus où le menaient les routes sur lesquelles il cheminait ». Les épreuves et les injustices quotidiennes, la guerre, tout le fait douter, le détourne ou le ramène à la foi. L'exil c'est aussi se découvrir autre face à une réalité autre. Et l'on retrouve ici un Mohammed Dib ou un Driss Chraïbi. M. H. 